\title{
ESSAY
}

\section{Covid-19 makes it harder for GPs to offer the quiet listening that made all the difference to me}

An anonymous patient explains how her GP used shared decision making to help her manage her distress. Quiet listening can empower patients to lead conversations about their own care, she says, but is threatened by the effects of covid-19, including more triage, remote care, and burnout among GPs

How are the kids doing? Did they go to school today? These were among the first things she asked me. This was the beginning of sustained, personalised care from a general practitioner whose talents were asking the right questions and quiet listening.

My husband was in an operating theatre, my head was spinning, and I hadn't slept in days. He needed a biopsy of lymph nodes close to his aorta. We knew that he was really sick. We didn't know what kind of cancer he had. I was terrified that he was dying (he was) and that there would be no cure (there wasn't).

Asking if the kids had gone to school was the right question. In the context of a late diagnosis of incurable cancer, it's a litmus test of how bad things are at home. In the following months, I became what can only be described as a walking waterfall. I was frightened of losing my husband. I was also frightened of losing the roof over our heads: the financial impact of cancer is something that too few people talk about.

The stress became unbearable. My husband exhausted NHS treatment and was negotiating access to clinical trials. He was in hospital for months at a time. My life was at an all time low. Navigating this patch of my life was like walking on quicksand.

\section{Hanging on to my mental health}

I didn't have flattened affect: I could still see joy and laugh. But I cried at night, as my husband groaned, sweating, startling, and waking with the pain that followed him everywhere. For months, I was hanging on to my mental health by a thread.

Discussing this with my GP was difficult. Her quiet listening was crucial. What followed was not a prescription for antidepressant drugs or an inpatient admission to a psychiatric ward, though both were very possible outcomes.

Instead, with my GP, I made a plan. You could call it a care plan, but it was instigated by the patient, not the health professional. A key feature was the joint decision to demedicalise my experience of distress. Together we agreed that I wouldn't start taking antidepressants: I chose to live with the distress and to find resilience. These discussions were very personal and practical and included where to get advice on managing financial pressures, balancing the demands of work and being a carer, and psychological support.

If things got really bad, I'd avoid going to the emergency department: she suggested other options for an acute mental health crisis that in her experience tended to work out better for patients, such as attending the charity Mind's sanctuary service. Avoiding unnecessary treatment saved the NHS money. My GP probably also helped me to avoid a psychiatric admission to hospital. None of this would have been possible without a GP who knew, and practised, the art of quiet listening.

No algorithmically programmed chatbot could do what she did in conveying humanity and allowing me to lead a clinical conversation. Entering "thoughts of suicide and self-harm" into an online triage tool or virtual symptom checker could not have produced the same outcome as I experienced through face-to-face care, or the same efficiency and value for the NHS.

\section{Truly personalised and demedicalised care}

Our conversation was about tailoring care to the individual: finding the right solution for me. This was personalised care in action. It speaks to the sharp end of conversations about the limits of the biomedical and clinical sciences to medical practice. ${ }^{1}$

The BMJ's Too Much Medicine campaign has focused on changing clinicians' behaviour by identifying diagnostic practice and treatments that are unlikely to benefit most patients (www.bmj.com/too-muchmedicine). What may be missing is a concurrent emphasis on empowering patients. How can clinical practice develop to enable patients jointly with clinicians to hold risk and manage uncertainty? How can practice develop to allow patients to lead conversations in which they can demedicalise their experiences of living with poor health or of dying?

I saw my GP a couple of times each month. The care I received was a masterclass in the highly skilled work of managing uncertainty and holding clinical risk in the community rather than referring to others. This helps create positive patient outcomes that avoid the harms of over-investigation and over-treatment, and it manages demand for health services. This is primary care's hugely valuable but often 
under-recognised contribution to the efficiency of the whole system.

\section{How to practise quiet listening}

My GP's willingness to play a supporting role was key. She elected that we jointly manage risk. By listening, rather than leading the conversation, she allowed me to make choices that were empowering while enabling me to demedicalise my experience of distress. She took her lead from me. I opened the conversation about whether I was depressed. I gave her my view of the evidence; I asked for her view. After a careful pause, she said, "I think you are not depressed."

We took it together from there. We talked about treatment options. Cognitive behavioural therapy works best when reframing can help adjust a patient's perspective on a problem. My GP and I agreed that this was not the right approach for my situation, where the problem itself was causing distress. Instead, we brainstormed together about who might locally offer psychological support based around acceptance and commitment therapy. The cancer charity Maggie's, as it turns out.

My GP's approach fits with newer thinking, exemplified in the SHERPA (sharing evidence routine for a person-centred plan for action) framework, ${ }^{2}$ for example, which values practical conversations that start by co-constructing with patients the nature of the problem. The focus is on simpler, more natural conversations about care that are appropriate for, and agreed with, individual patients.

\section{Creating quiet spaces}

How might quiet listening fit with active listening, often taught to students in medical school? Instead of an emphasis on listening with fascination, quiet listening is more about empathy in practice, about quiet spaces in conversations.

I am both a carer and a patient. Often my GP and I discussed both in the same consultation. Moving between the two conversations can be jarring for me- "How is your husband?" "Ah, it's been an interesting few weeks. He's broken his arm, his leg, and been hospitalised for two major internal bleeds." "Shall I examine that lump under your arm now?” This was a single conversation, but my GP paused after discussing my husband and watched me. My head was down, my eyes at the floor. When my body language told her I was ready-when I lifted my head, and looked at her-she smiled and asked if I was ready to be examined. It's subtle, but important, this ability to create quiet spaces within a consultation.

With an emphasis on patient activation, which focuses on what you can do, it can be hard to find space for conversations about what you can't do. Quiet listening makes space to speak about worrying you can't feed your children properly, not being able to buy their shoes, not having money to pay for a funeral. These are some of the things that distressed me the most. The Dutch anthropologist Annemarie Mol points out that care "makes space for what is not possible."3 Quiet listening is an important part of this.

\section{Continuity of care}

A doctor who I trust and who knows me well is crucial in enabling quiet listening and to leading conversations about my own care. Seeing the same doctor over time also means that I don't have to repeat my story to multiple different doctors. Once is enough: some things are not fun to talk about. Seeing the same GP over time has a survival advantage similar to many drugs and complex interventions, evidence shows. ${ }^{4}$ High relational continuity is associated with lower mortality, better self-management of long term conditions, and fewer admissions to hospital. ${ }^{5}$
The same GP can notice changes that would not be obvious to a doctor who doesn't know me. I'm prone to ironic humour and making inappropriate jokes, for example, even about what was happening to me then. If I stop doing this, I'm in trouble. Losing my sense of humour indicates seriously deteriorating mental health. A GP who didn't know me well couldn't read that.

Since the pandemic, quiet listening and relationship based care have arguably become even more important, ${ }^{6}$ particularly for more than a million people in the UK with long covid 7 and those whose conditions have deteriorated while they have been unable to get treatment and care-including five million patients stuck on long waiting lists for hospital treatment in England. ${ }^{8}$

\section{Remote care and the future of quiet listening}

At the same time, covid-19 could have long term effects on the ability of GPs to offer quiet listening and face-to-face care to patients. In the acute phase of the pandemic, NHS England was right to instate remote "total triage" and a shift towards remote consulting to protect patients and NHS staff. ${ }^{9}$ But what might be lost with this model, and with what unintended costs?

With so much recent concern about rising numbers of appointments and demand on general practices, ${ }^{10}$ have we thought carefully enough about the risk of telephone triage adding to clinicians' workload through duplication, for which there is good evidence ${ }^{11}$

We cannot assume remote care is the best option for most patients in the long term. ${ }^{12}$ Early evaluation of "remote by default" care finds over-protocolised general practice can come with risk. ${ }^{13}$ Case based judgment is needed to decide if remote consultation is best for a particular patient at a particular time. Complexity in primary care consultations include, for example, "doorknob disclosures," when patients mention something crucial as they are leaving, and early detection of cancer through clinical intuition and timely investigation. In lung cancer, ${ }^{14}$ for example, clinicians believe face-to-face appointments are the best option for most purposes, especially breaking bad news.

Positioning remote care as the norm from which the traditional face-to-face consultation would deviate sits uncomfortably. ${ }^{13}$ Decisions should be guided by evidence on the benefits as well as possible unintended harms.

Alongside this, we should be careful not to take for granted the benefits of care that might be deemed "old fashioned" by some. I never set out to find a GP whose talent was quiet listening and relationship based care. I didn't know I'd need her. It was pure luck that, when I needed a GP who offered this kind of care, I had one. In an age of machine learning and techno-optimism, the artful skill of quiet listening can easily be undervalued. But it makes a crucial difference to the quality of patient care and to value for the NHS.

\section{The challenge ahead for general practice}

General practice is now at a crossroads. ${ }^{15}$ Demand for appointments is rising, as is concern about the harms to GPs through the "moral injury" that comes from being unable to provide the kind of care they believe that patients need. ${ }^{10}$

We previously sought to find practical ways to provide continuity alongside better access to primary care. ${ }^{16}$ Now we need thinking that allows general practice to harness the benefits of remote consultations while holding on to the value to patients and to clinicians inherent in relationship based care and quiet listening. One starting point may be the realisation of National Voices' vision for inclusive and personalised care. ${ }^{17}$ 
Provenance and peer review: Commissioned; not externally peer reviewed.

Competing interests: I have read and understood BMJ policy on declaration of interests and have no relevant interests to declare.

To send a message to the author, please contact the commissioning editor, Richard Hurley, rhurley@bmj.com

1 Marshall M, Cornwell J, Collins ARethinking Medicine Working Group. Rethinking medicine. BMJ 2018;363:k4987. doi: 10.1136/bmj.k4987. pmid: 30545822

2 Jack E, Maskrey N, Byng R. SHERPA: a new model for clinical decision making in patients with multimorbidity. Lancet2018;392:1397-9. doi: 10.1016/S0140-6736(18)31371-0 pmid: 30343853

3 Mol A. The logic of care: health and the problem of patient choice. Routledge, 2008: 25. doi: 10.4324/9780203927076.

4 Pereira Gray DJ, Sidaway-Lee K, White E, Thorne A, Evans PH. Continuity of care with doctors-a matter of life and death? A systematic review of continuity of care and mortality. BMJ Open 2018;8:e021161. doi: 10.1136/bmjopen-2017-021161. pmid: 29959146

5 Palmer W, Hemmings N, Rosen R, Keeble E, Williams S, Imison C. Improving access and continuity in general practice: Practical and policy lessons. Nuffield Trust, 2018. https://www.nuffieldtrust.org.uk/files/2019-01/continuing-care-summary-final-.pdf

6 Atherton H, Briggs T, Chew-Graham C. Long covid and the importance of the doctor-patient relationship. BrJ Gen Pract 2021;71:54-5. doi: 10.3399/bjgp21X714641. pmid: 33509811

7 Prevalence of ongoing symptoms following coronavirus (covid-19) infection in the UK: 1 April 2021. https://www.ons.gov.uk/peoplepopulationandcommunity/healthandsocialcare/conditionsanddiseases/bulletins/prevalenceofongoingsymptomsfollowingcoronaviruscovid19infectionintheuk/1april2021

$8 \quad$ NHS England. Consultant-led referral to treatment waiting times data 2020-21 15 April 2021. www.england.nhs.uk/statistics/statistical-work-areas/rtt-waiting-times/rtt-data-2020-21/\#Feb21.

9 NHS England, NHS Improvement. Advice on how to establish a remote 'total triage' model in general practice using online consultations. March 2020. https://www.worcslmc.co.uk/cache/downloads/20200327---Remote-total-triage-blueprint.pdf

10 Cracks are starting to show"-crisis in primary care can no longer be ignored, says BMA in response to GP appointment data. BMA. 17 June 2021. https://www.bma.org.uk/bma-mediacentre/cracks-are-starting-to-show-crisis-in-primary-care-can-no-longer-be-ignored-says-bmain-response-to-gp-appointment-data

11 Newbould J, Abel G, Ball S, etal. Evaluation of telephone first approach to demand management in English general practice: observational study. BMJ 2017;358:j4197. doi: 10.1136/bmj.j4197. pmid: 28954741

12 National Voices. The doctor will zoom you now: getting the most out of the virtual health and care experience. https://www.nationalvoices.org.uk/sites/default/files/public/publications/the_dr_will_zoom_you_now___insights_report-min.pdf

13 Greenhalgh T, Rosen R. Remote by default general practice: must we, should we, dare we?Br Gen Pract 2021;71:149-50. doi: 10.3399/bigp21X715313. pmid: 33771790

14 MSD. Virtual consultations in the lung cancer pathway. What works for patients and healthcare professionals? MSD. Nov 2020. https://www.msdconnect.co.uk/static/mciuk/pdf/Virtual_consultations_in_the_lung_cancer_pathway.pdf

15 Gray DP, Freeman G, Johns C, Roland M. Covid 19: a fork in the road for general practice. BMJ 2020;370:m3709. doi: 10.1136/bmj.m3709. pmid: 32988832

16 Palmer W, Hemmings N, Rosen R, et al. Improving access and continuity in general practice. https://www.nuffieldtrust.org.uk/files/2019-01/improving-access-and-continuity-in-generalpractice-evidence-review-final-update-01-2019.pdf

17 National Voices. Unlocking the digital front door: a call to action. Insight report and call to action from projects in 2020-2021. May 2021. https://www.nationalvoices.org.uk/sites/default/files/public/publications/unlocking_the_digital_front_door_call_to_action.pdf 